\title{
Planar integrated magnetics design in wide input range DC-DC converter for fuel cell application
}

Ouyang, Ziwei; Zhang, Zhe; Thomsen, Ole Cornelius; Andersen, Michael A. E.; Poulsen, Ole; Bjorklund, Thomas

\section{Published in: \\ ECCE 2010}

Link to article, DOI:

10.1109/ECCE.2010.5618406

Publication date:

2010

Document Version

Publisher's PDF, also known as Version of record

Link back to DTU Orbit

Citation (APA):

Ouyang, Z., Zhang, Z., Thomsen, O. C., Andersen, M. A. E., Poulsen, O., \& Bjorklund, T. (2010). Planar integrated magnetics design in wide input range DC-DC converter for fuel cell application. In ECCE 2010 https://doi.org/10.1109/ECCE.2010.5618406

\section{General rights}

Copyright and moral rights for the publications made accessible in the public portal are retained by the authors and/or other copyright owners and it is a condition of accessing publications that users recognise and abide by the legal requirements associated with these rights.

- Users may download and print one copy of any publication from the public portal for the purpose of private study or research.

- You may not further distribute the material or use it for any profit-making activity or commercial gain

- You may freely distribute the URL identifying the publication in the public portal 


\title{
Planar Integrated Magnetics Design in Wide Input Range DC-DC Converter for Fuel Cell Application
}

\author{
Ziwei Ouyang ${ }^{1}$, Zhe Zhang ${ }^{1}$, Ole C. Thomsen ${ }^{1}$, Michael A. E. Andersen ${ }^{1}$, Ole Poulsen ${ }^{2}$, and Thomas Björklund ${ }^{2}$ \\ 1. Department of Electrical Engineering, \\ Technical University of Denmark, \\ Kgs. Lyngby, DK-2800, Denmark, zo@elektro.dtu.dk \\ 2. Flux A/S - Europe \\ Asnæs, DK-4550, Denmark
}

\begin{abstract}
In the most power electronics converters, the overall volume is mainly determined by the number of parts and the size of passive components. Integrated magnetics and planar magnetics techniques therefore have been an excellent option in order to reduce the count and the size of magnetic components, hereby increasing the power density of converters. A new planar integrated magnetics (PIM) technique for a phase-shift plus duty cycle controlled hybrid bi-directional DC/DC converter is presented and investigated in this paper. The main magnetic components including one boost inductor and two independent transformers are integrated into an E-I-E core geometry. Utilizing the flux cancellation as the principle of uncoupling, the transformers and the boost inductor are integrated, to reduce the total ferrite volume and core loss. The transformers and inductor are wound in the outer legs and the center legs respectively. The uncoupling effect between them is determined by the winding connections. The middle I-core provides a shared low reluctance flux path, uncoupling the two independent transformers. With the air gaps shift into the center legs, the magnetizing inductance of transformers will not be decreased due to there is no air gap throughout the flux paths generated by the two transformers. The new PIM structure can be extended to other topologies. To verify the validity of design approach and theoretical analysis, a lab prototype with PIM has been built, and tested. Comparing with the discrete structure, the result demonstrated a great improvement in profile and volume without sacrificing electrical performance.
\end{abstract}

Index Terms-planar integrated magnetics, transformer, inductor, uncoupling, hybrid DC-DC converter, and fuel cell.

\section{INTRODUCTION}

Nowadays, the hybrid system based on fuel cells (FCs) and super-capacitors (SCs) as an environmentally renewable energy system has been applied in many fields, such as hybrid electric vehicle (HEV), uninterruptible power supply (UPS) and so on. The paper [1] proposes a novel phase-shift plus duty cycle controlled hybrid bi-directional DC/DC converter. As shown in Fig. 1, the converter utilizes the boosttype input structure to limit the ripple current of the FCs, and the two transformers $T 1$ and $T 2$ are employed to couple the half-bridge and the full-bridge circuits respectively. The hybrid structure can be operated in different modes in terms of the different input voltage values. Phase-shift ZVS technique is used in bi-directional DC/DC converters as well since it can realize ZVS for all switches without auxiliary switches. However, when the amplitude of input voltage is not matched with that of output voltage, the current stresses and RMS currents of the converter become higher. Therefore the duty cycle control also is implemented in this converter to reduce current stress and conduction losses, and to expand ZVS range.

The topology proposed in the paper [1] also has many drawbacks including the quantity and size of components, the complexity and the cost. In order to satisfy the requirements of modern power electronics application, magnetics integration with planar core has proven to be an effective means of reducing DC/DC converter size and cost and increasing converter efficiency [2]-[9]. Planar magnetic techniques are usually chosen for magnetics integration to improve thermal behavior and reduce profile as well as easy mass production attached with PCB windings. In recent years, most of efforts in integration magnetics focus on the currentdoubler rectifier due to its suitability for low-output-voltage and high-output-current applications [2]-[6]. A 1-kW $300 \mathrm{~V}-$ $400-\mathrm{V}$ input $48-\mathrm{V}$ output $\mathrm{AHBC}$ asymmetrical half-bridge PWM converter employing the integrated $\mathrm{L}-\mathrm{L}-\mathrm{C}-\mathrm{T}$ module is constructed in the reference [8]. Detailed suggestions are given of how one generic, integrated LCT component could be used to implement various resonant converter topologies by merely reconfiguring the external terminals of the integrated component [9]. A new E-I-E core geometry integrating the boost inductor $L 1$ and the two independent transformers $T 1$ and $T 2$ is proposed in this work. Utilizing the flux cancellation as the principle of uncoupling, the transformers and the boost inductor are integrated, to reduce the quantity of components, the total ferrite volume, the core loss. As a case study, the design and performance of the integrated generation is compared with a standard discrete generation.

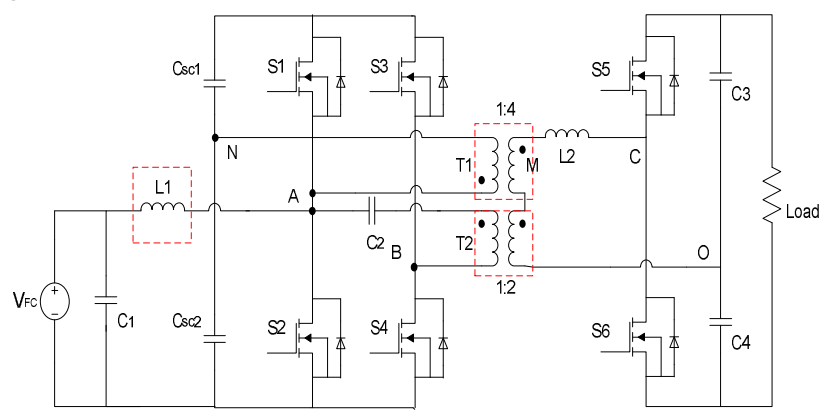

Fig. 1. Hybrid bidirectional DC/DC converter topology.

\section{Operation PRINCIPLES OF The Hybrid Bi-Directional DC/DC CONVERTER}

As shown in Fig. 1, a boost type half bridge converter with the switches $S_{1}$ and $S_{2}$ operating by $50 \%$ duty cycle is in the primary side of the transformer $T_{1}$, and super-capacitors $C_{\mathrm{SC} 1}$ 
and $C_{\mathrm{SC} 2}$ connect on the variable low voltage $\mathrm{DC}$ bus as an auxiliary energy source. When input voltage $V_{F C}$ is variable in a wide range, $S_{3}$ and $S_{4}$ are controlled by the duty cycle, $D 2$, to change the operating modes. The two transformers, $T_{1}$ and $T_{2}$, with the independent primary windings as well as the secondary windings in series are utilized to realize galvanic isolation and boost the low input voltage from the primary side. Voltage doubler circuit is used in secondary side to improve voltage conversion ratio further. The inductor $L_{2}$ in secondary side is utilized as a phase-shift inductor to achieve soft-switching ZVS for all switches. The operational modes can be divided into boost mode and buck mode due to different power flow directions. In Boost mode, where the energy flows from low voltage side to high voltage side, there are two sub-modes, two-voltage-level mode and threevoltage-level mode, depending on different input and output voltage value. The counterpart is defined as Buck mode. Actually, when the duty cycle of $S_{3}$ and $S_{4}$ is identical to the duty cycle of $S_{1}$ and $S_{2}$, the three-voltage-level mode will be identical to the two-voltage-level mode. Hereby, only the three-level-mode is analyzed below. One complete switching cycle can be divided into ten intervals as shown in Fig. 2 .

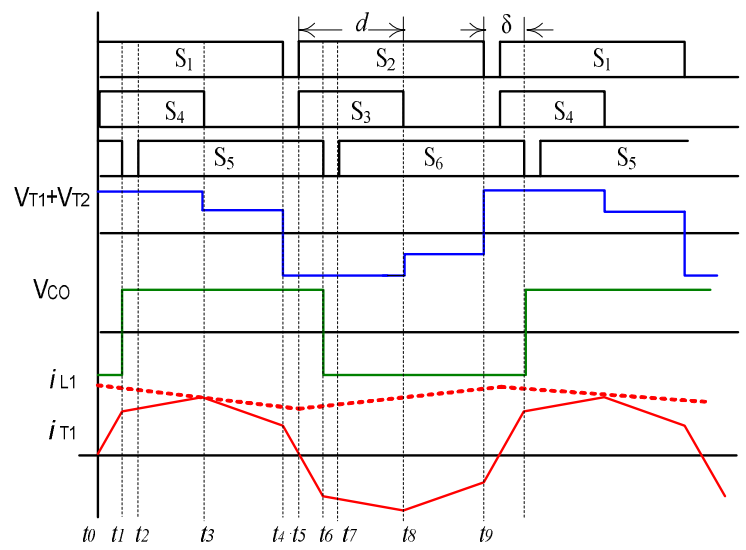

Fig. 2. Key waveforms with three voltage levels in Boost mode.

1) Stage $1\left(t_{0}-t_{1}\right): S_{1}, S_{4}$ and $S_{6}$ are conducting. The voltage on $L_{2}$ is $v_{T 1 s}+v_{T 2 S}+v_{C O}$, so the $i_{L 2}$ will increase linearly. $I_{L 1}$ goes though the body-diode $D_{\mathrm{S} 1}$ of switching $\mathrm{S} 1$;

2) Stage $2\left(t_{1}-t_{2}\right)$ : At $t_{1}, S_{6}$ is turned off. The inductor $L_{2}$ begins to resonate with the stray capacitors $C_{\mathrm{S} 5}$ and $C_{\mathrm{S} 6}$ of switching S5 and S6. When voltage on $C_{\mathrm{S} 5}$ reduces to zero, the body-diode of $S_{5}$ start to conduct, and the voltage $v_{C O}$ changes the direction. Hereby $v_{L 2}$ equals to $v_{T 1 s}+v_{T 2 s}-v_{C O}$;

3) Stage $3\left(t_{2}-t_{3}\right)$ : At $t_{2}, S_{5}$ is turned on under ZVS. The current paths are the same as those in the stage 2;

4) Stage $4\left(t_{3}-t_{4}\right)$ : At $t_{3}, S_{4}$ is turned off. The inductor $L_{2}$ begins to resonate with the stray capacitors $C_{\mathrm{S} 3}$ and $C_{\mathrm{S} 4}$ of switching S3 and S4. When the voltage cross $S_{3}$ reduces to zero, $D_{\mathrm{S} 3}$ is therefore forward based. The voltage cross the primary winding of $\mathrm{T}_{2}$ is clamped to zero. So $v_{L 2}$ equals to $v_{T 2 s}-v_{C O}$;

5) Stage $5\left(t_{4}-t_{5}\right)$ : At $t_{4}, S_{1}$ is turned off. The inductor $L_{2}$ begins to resonate with the stray capacitors $C_{\mathrm{S} 1}$ and $C_{\mathrm{S} 2}$ of switching $\mathrm{S} 1$ and $\mathrm{S} 2 . C_{\mathrm{S} 2}$ is discharged from $2 V_{F C}$. The rate of change depends on the magnitude $i_{\mathrm{T} 1 \mathrm{p}}+i_{\mathrm{T} 2 \mathrm{p}}-I_{\mathrm{Ldc}}$. At $t_{5}, v_{\mathrm{CS} 2}$, attempts to overshoot the negative rail. $D_{\mathrm{S} 2}$ is forward biased. During this period, $S_{2}$ can be turned on under ZVS.

After $t_{5}$, the second half cycle starts which is similar to the first half cycle. More detailed description of the principle can be found in the paper [1].

\section{New PIM Module STRUCTURE}

The conventional IM design currently uses soft-ferrite E-I or E-E core structures. The proposed structure in this work is to integrate two independent transformers $T_{1}, T_{2}$ and input boost inductor $L_{1}$ with a new E-I-E core geometry. As shown in Fig.3, the windings of each transformer are equally divided into the outer legs of E-cores. In transformer $T_{1}, \mathrm{P}_{1} / 2$ and $\mathrm{S}_{1} / 2$ represent half of primary winding and half of secondary winding respectively. $\mathrm{P}_{2} / 2$ and $\mathrm{S}_{2} / 2$ are the same properties for the transformer $T_{2} . L_{1-1}$ in parallel with $L_{1-2}$ wound in the center legs of E-cores to form as the boost inductor $L_{l}$. The middle I-core provides a shared flux return path. $\varnothing_{1}$ and $\varnothing_{2}$ represent $\mathrm{AC}$ flux generated by the transformers $T_{1}$ and $T_{2}$ respectively. By arranging the directions of the windings on the outer legs for each transformer, zero AC flux can be achieved in the center legs. $\varnothing_{1}$ and $\varnothing_{2}$ have their own flux paths due to a low reluctance path is provided by shared Icore which means the two transformers $T_{1}$ and $T_{2}$ are uncoupling. Because $\varnothing_{1}$ is not equivalent to $\varnothing_{2}$ in this work as analyzed in Fig.4, AC flux will partially cancel in shared Icore. DC flux $\varnothing_{3}$ generated by the boost inductor $L_{1}$ goes through the center legs of E cores. Half of $\varnothing_{3}$ runs in outer legs of E-cores and no DC flux exists in shared I-core due to complete cancellation effect (see black line in Fig.3). As seen in Fig.3, half of DC flux $\varnothing_{3}$ promotes the AC flux both $\varnothing_{1}$ and $\varnothing_{2}$ in right side and the other half of DC flux $\varnothing_{3}$ lower the AC flux in left side. Taken together, DC flux $\varnothing_{3}$ will not affect the AC flux generated by the transformers. Therefore, the two uncoupled transformers and one boost inductor can be integrated into the new geometry.

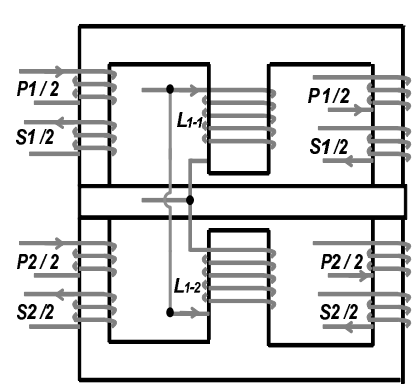

(a)

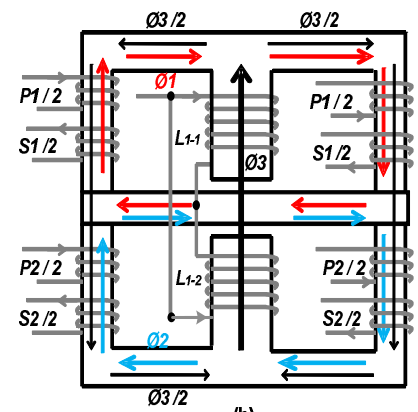

(b)
Fig. 3. (a) Proposed E-I-E integrated magnetic structure; (b) Analytical instantaneous flux distribution.

In term of this new geometry, several advantages can be concluded as below,

(1) Air gaps can be placed in the center legs which cause lower fringing flux as well as EMI problem comparing with air gap in outer legs [4], [6]. Standard core in industry application and mechanically stabilization are both advantages in the structure. 
(2) Magnetizing inductances of transformers will not be decreased due to there is no airgap throughout the flux path generated by the two transformers.

(3) Low cost because of the magnetic cores can be saved by integration.

(4) Low profile. The integrated method provides a small footprint for magnetic components, which can increase the power density required by the space restriction in automotive and integrated application.

(5) Flexibility. The method can be extended into many other topologies.

\section{Magnetics Design CONSIDERATION}

\section{A. Design Specifications}

The specifications of the hybrid circuit and the integrated module are shown in Table I. In Boost mode, the converter works under the three-level-mode to limit the peak current value in primary side of the transformers, through the duty cycle control on $S_{3}$ and $S_{4}$, as shown in Fig.2. The transferred power can be controlled by the phase-shift angle $\delta$ between $S_{l}$ and $S_{5}$. Magnetics design in the phase-shift DC/DC converter is very important which determines the transferred power, ZVS range and power losses of converters. As referring most of publications about this kind of converters, the detail processes of magnetics design are rarely included and only the values of magnetic components are mentioned in the specification.

\section{B. Magnetics Design}

Although the currents of transformers have a bigger AC ripples as shown in Fig.2, the current ripple will not contribute the core loss due to the induced AC flux are only caused by the excitation voltage on transformer side rather than the load current. It is impossible to completely cancel the AC flux $\varnothing_{1}$ and $\varnothing_{2}$ in shared I-core due to both the amplitudes and duty cycles of excitation voltages on transformers $T_{1}$ and $T_{2}$ are different. In order to reduce the core loss as much as possible, an appropriate turns ratio between $N_{1}$ and $N_{2}$ should be chosen where $N_{1}$ and $N_{2}$ are the primary number of turns on the transformers $T_{1}$ and $T_{2}$

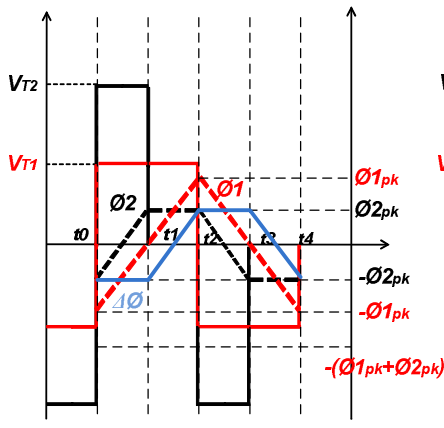

(a)

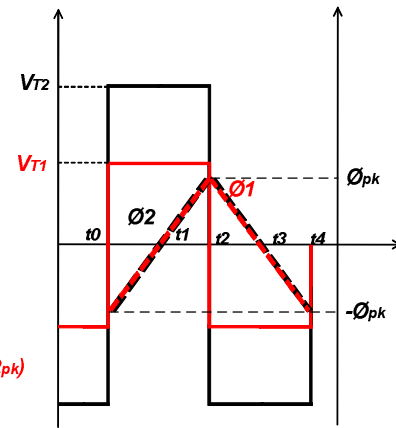

(b)
Fig. 4. (a) The excitation voltages of transformers and their working AC flux waveforms when three-level-mode control (duty cycle control on $\mathrm{S}_{3}$ and $\mathrm{S}_{4}$ ); (b) The excitation voltages of transformers and their working $\mathrm{AC}$ flux waveforms when two-level-mode control (duty cycles on $\mathrm{S}_{3}$ and $\mathrm{S}_{4}$ are $50 \%$ );
Table I

Specifications of the Hybrid Converter

\begin{tabular}{|c|c|}
\hline Parameters & Values \\
\hline Input voltage $V_{F C}(\mathrm{~V})$ & $20-40$ \\
\hline Output voltage $V_{o}(\mathrm{~V})$ & 400 \\
\hline Duty cycle of $\mathrm{S}_{1}, \mathrm{~S}_{2}$ and $\mathrm{S}_{5}, \mathrm{~S}_{6}$ & 0.5 \\
\hline Duty cycle of $\mathrm{S}_{3}$ and $\mathrm{S}_{4}$ & $0.2-0.5$ \\
\hline Switching frequency $f_{s}(\mathrm{kHz})$ & 100 \\
\hline DC decoupling capacitance $\mathrm{C}_{2}(\mathrm{uF})$ & 10 \\
\hline Auxiliary inductor $\mathrm{L}_{2}(\mathrm{uH})$ & 40 \\
\hline Boost inductor $\mathrm{L}_{1}(\mathrm{uH})$ & 10 \\
\hline Turns ratio of $\mathrm{T}_{1}$ & $1: 4$ \\
\hline Turns ratio of $\mathrm{T}_{2}$ & $1: 2$ \\
\hline
\end{tabular}

respectively. As shown in Fig. 4, when the duty cycles of $S_{3}$ and $S_{4}$ are also equal to $50 \%$, the flux can be cancelled in shared I-core completely if the $N_{2}$ is two times than $N_{l}$; when the duty cycles of $S_{3}$ and $S_{4}$ are below $50 \%$, the fluxes will be partially cancelled.

According to Faraday's law and voltage-second rule, the peak flux densities of $T_{I}$ and $T_{2}$ can be found,

$$
\begin{aligned}
B_{p k_{-} T 1} & =\frac{V_{F C}}{4 \cdot f \cdot N_{1} \cdot A_{e}} \\
B_{p k_{-} T 2} & =\frac{V_{F C} \cdot D}{f \cdot N_{2} \cdot A_{e}}
\end{aligned}
$$

where $D$ is the duty cycle of switching $S_{3}$ and $S_{4}, f$ is switching frequency and $A_{e}$ is cross-section in the outer leg of core.
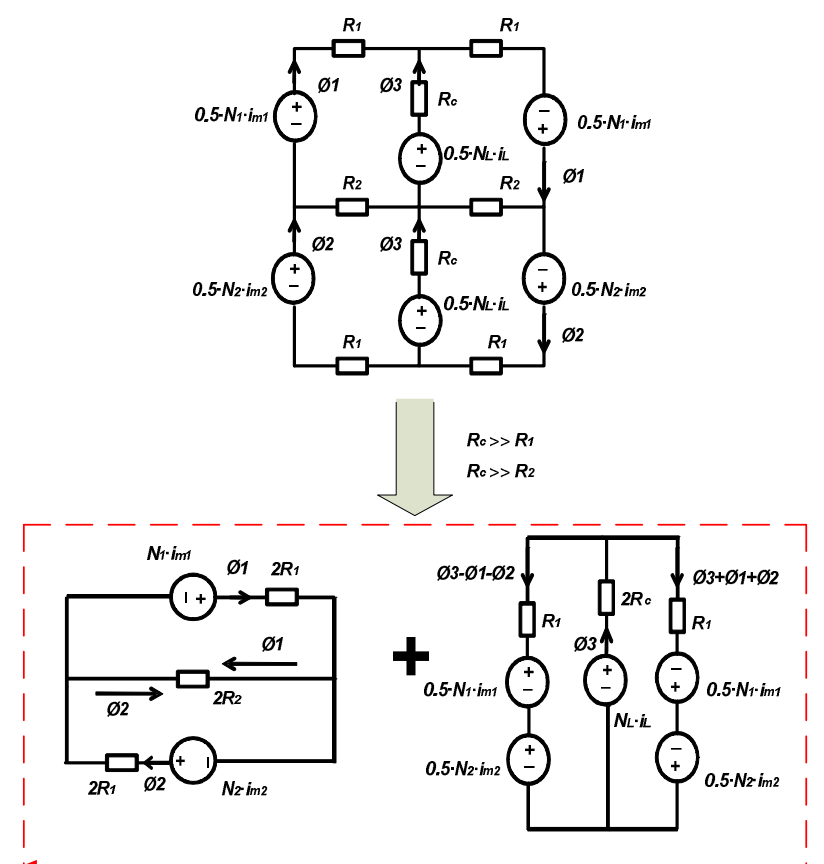

Fig. 5. The reluctance model of the new PIM structure. 
Fig.5 shows the magnetic reluctance model of the new PIM structure where $R_{1}$ and $R_{2}$ are the reluctance of each outer leg of E-core and half shared I-core respectively as well as $R_{C}$ represents the reluctance of the center leg of E-core. $R_{C}$ is much more than $R_{1}$ and $R_{2}$ due to the air gap which prevents the flux saturation. Since the two transformers are uncoupling with the boost inductor, the equivalent model can be divided into the two parts. The left part in dashed rectangle represents the magnetic circuit of the two transformers $T_{1}$ and $T_{2}$. Zero AC flux generated by the transformers is going through the boost inductor and the flux $\varnothing_{3}$ from the inductor has been cancelled in the magnetic circuit. The flux $\varnothing_{1}$ and $\varnothing_{2}$ in shared I-core will be partially or completely cancelled depending on the duty cycle of $S_{3}$ and $S_{4}$ as analyzed in the previous. As seen in the right part of dashed rectangle, it represents the magnetic circuit of the boost inductor. $\varnothing_{1}$ and $\varnothing_{2}$ will not go through the center leg but still existing in the outer legs, the equivalent flux on the both side legs are different this is the fact that the half of flux $\varnothing_{3}$ is blocking the flux $\varnothing_{1}$ and $\varnothing_{2}$ and the other half is adding them.

Based on the equivalent magnetic model in Fig.5, the major flux directions can be determined, as well as the leakage flux through the air is negligible. The equations (3) and (4) can be obtained from the left part of magnetic circuits,

$$
\begin{aligned}
& N_{1} \cdot i_{m_{1}}=\phi_{1} \cdot 2 R_{1}+\left(\phi_{1}-\phi_{2}\right) \cdot 2 R_{2} \\
& N_{2} \cdot i_{m_{2}}=\phi_{2} \cdot 2 R_{1}+\left(\phi_{2}-\phi_{1}\right) \cdot 2 R_{2}
\end{aligned}
$$

while the equations (5) and (6) can be obtained from the right part,

$$
\begin{gathered}
N_{L} \cdot i_{L}=\phi_{3} \cdot 2 R_{c}+\left(\phi_{3}-\phi_{1}-\phi_{2}\right) \cdot R_{1}+0.5 N_{1} \cdot i_{m 1}+0.5 N_{2} \cdot i_{m 2} \\
N_{1} \cdot i_{m 1}+N_{2} \cdot i_{m 2}=2\left(\phi_{1}+\phi_{2}\right) \cdot R_{1}
\end{gathered}
$$

Because the flux $\varnothing_{1}$ and $\varnothing_{2}$ are different when duty cycle control is used in the converter as shown in Fig.4, four intervals can be uniformly described combining with the above equations and Faraday's law, $(D<0.5, T$ is period)

1) Case 1 [0 DT] and [0.5T (0.5+D)T]:

$$
L_{m 1}=\frac{N_{1}^{2}}{2 R_{1}} ; L_{m 2}=\frac{N_{2}^{2}}{2 R_{2}} ; L_{\text {boost }}=\frac{N_{L}^{2}}{2 R_{c}+R_{1}}
$$

2) Case 2 [DT 0.5T] and $[(0.5+D) T \sim T]$ :

$$
L_{m 1}=\frac{N_{1}^{2}}{2 R_{1}+R_{2}} ; L_{m 2}=\frac{N_{2}^{2}}{2 R_{2}} ; L_{\text {boost }}=\frac{N_{L}^{2}}{2 R_{c}+R_{1}}
$$

where $N_{2}=2 N_{l}, \quad R_{C}>>R_{l}$. Since the two E-cores are symmetrical and no air gap in both outer legs of E-core and shared I-core, it can be assumed that $R_{1}=2 R_{2}$.

According to Ampere's law, the peak flux density $B_{p k_{L} L}$ for the boost inductor is given by,

$$
B_{p k_{-} L}=\frac{\mu_{0} \cdot N_{L} \cdot I_{p k}}{l_{g}}
$$

where $l g$ is the total length of air gap in the center legs. In order to avoid the flux saturation in PIM module, the following equations are required,

$$
B_{p k_{-} T 1}+B_{p k_{-} L}=\frac{V_{F C}}{4 \cdot f \cdot N_{1} \cdot A_{e}}+\frac{\mu_{0} \cdot N_{L} \cdot I_{p k}}{l_{g}} \leq B_{s a t}
$$

The maximum allowed flux density ripple $\Delta B_{L}$ is given by the maximum peak flux density for the core material $B_{p k_{L} L}$ and the ratio of allowed peak-to-peak ripple current $(\Delta I)$ to the peak current $\left(I_{p k}\right)$.

$$
\Delta B_{L}=B_{p k_{-} L} \cdot \frac{\Delta I}{I_{p k}}
$$

The flux density ripple shall be less than or equal to the maximum allowed value given by (9). According to Faraday's law, the required number of turns is found from (10).

$$
N \geq \frac{V_{F C} \cdot T}{4 A_{e} \cdot B_{p k}} \cdot \frac{I p k}{\Delta I}
$$

High ripple current causes increased core loss and power loss in the transistors and low ripple current requires a high number of inductor turns, which results in high conduction losses in the integrated magnetics. Experience has shown that a good trade-off is a ripple factor of two [5].

Accordingly, the results of magnetics design in PIM are shown in Table II.

Table II

Magnetics Design Results

\begin{tabular}{|c|c|}
\hline Parameters & Values \\
\hline Number of turns in primary of $\mathrm{T}_{1}\left(N_{l}\right)$ & 4 \\
\hline Number of turns in primary of $\mathrm{T}_{2}\left(N_{2}\right)$ & 8 \\
\hline Number of turns for boost inductor $\left(N_{L}\right)$ & 4 \\
\hline Each air gap length $\left(l_{g} / 2\right)$ & $0.5 \mathrm{~mm}$ \\
\hline Cross-section of core $(2 A e)$ & $519 \mathrm{~mm}^{2}$ \\
\hline Core type & EILP 64 \\
\hline Core material & Ferrite N87 \\
\hline Max allowed current of inductor $\left(I_{p k}\right)$ & $50 \mathrm{~A}$ \\
\hline Peak flux density of transformer $\mathrm{T}_{1}\left(B_{\left.p k_{-} T 1\right)}\right.$ & $0.1 \mathrm{~T}$ \\
\hline Peak flux density of transformer $\mathrm{T}_{2}\left(B_{\left.p k_{-} T 2\right)}\right.$ & $0.1 \mathrm{~T}$ \\
\hline Peak flux density of boost inductor $\left(B_{p k_{-} L}\right)$ & $0.25 \mathrm{~T}$ \\
\hline
\end{tabular}

\section{SimUlation AND EXPERIMENTAL RESUltS}

To verify the validity of design approach and theoretical analysis, a 2D simulation model linked with external circuit has been built in FEA tool. It completely coincides with parameters shown in Table I and Table II. Fig.6 shows an instantaneous distribution of flux density in the core of PIM 


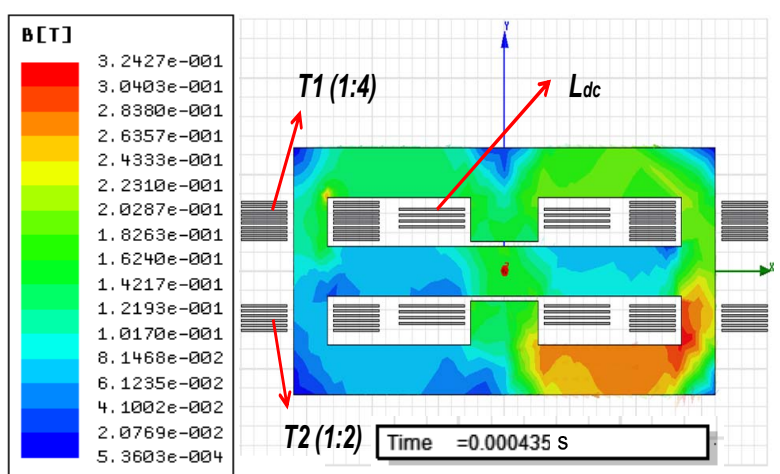

Fig. 6. Discrete hybrid DC/DC converter generation.

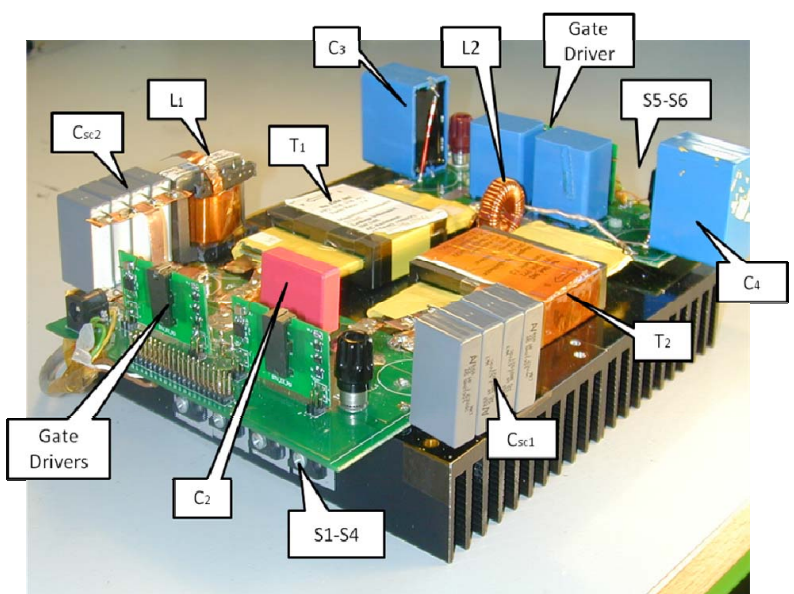

Fig. 7. Discrete hybrid DC/DC converter generation.

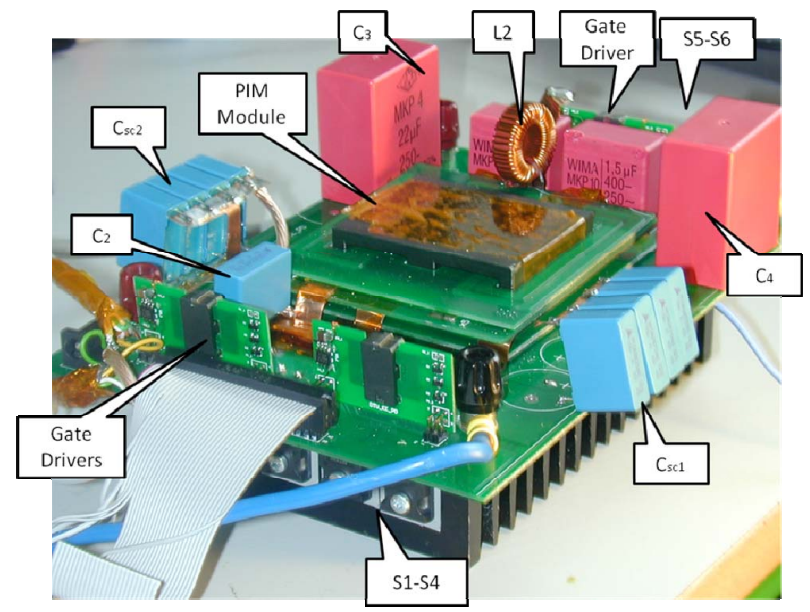

Fig. 8. Integrated generation with the proposed PIM

structure. The right part has stressed color because half of $\emptyset_{3}$ overlaps with $\varnothing_{1}$ and $\varnothing_{2}$. In reverse, these flux counteract in left part. Partial cancellation between $\varnothing_{1}$ and $\varnothing_{2}$ is in shared I-core and no DC flux throughout it. Therefore, simulation has proved that the uncoupling effect is successful in the new PIM structure.

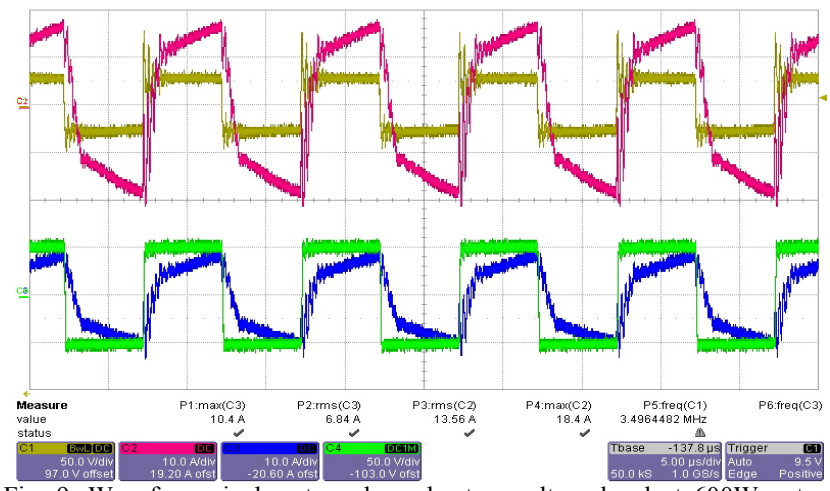

Fig. 9. Waveforms in boost mode under two-voltage-level at $600 \mathrm{~W}$ output power. $\mathrm{CH} 1: V_{A N}(50 \mathrm{~V} / \mathrm{div}) ; \mathrm{CH} 2: i_{\mathrm{T} 1}(10 \mathrm{~A} / \mathrm{div}) ; \mathrm{CH} 3: i_{\mathrm{T} 2}(10 \mathrm{~A} / \mathrm{div}) ; \mathrm{CH} 4$ : $V_{A B}(50 \mathrm{~V} / \mathrm{div})$.

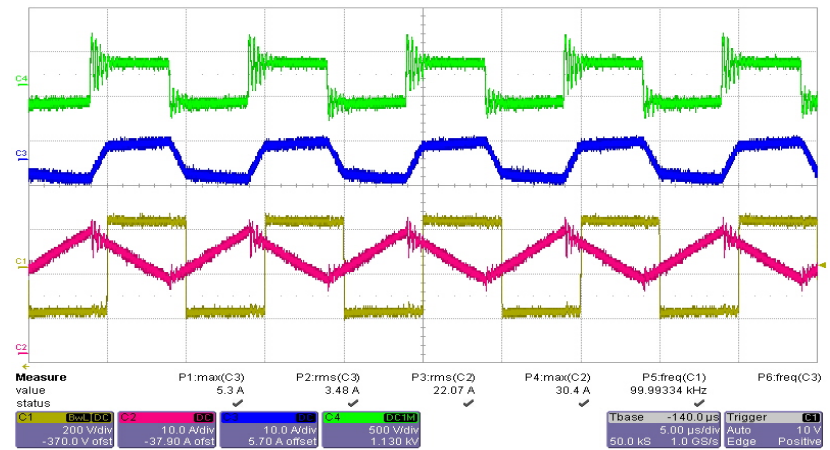

Fig. 10. Waveforms in boost mode under two-voltage-level at $600 \mathrm{~W}$ output power. $\mathrm{CH} 1: V_{C O}(200 \mathrm{~V} / \mathrm{div}) ; \mathrm{CH} 2: i_{\mathrm{L} 1}(10 \mathrm{~A} / \mathrm{div}) ; \mathrm{CH} 3: i_{\mathrm{L} 2}(10 \mathrm{~A} / \mathrm{div}) ; \mathrm{CH} 4$ : $V_{M O}(500 \mathrm{~V} / \mathrm{div})$

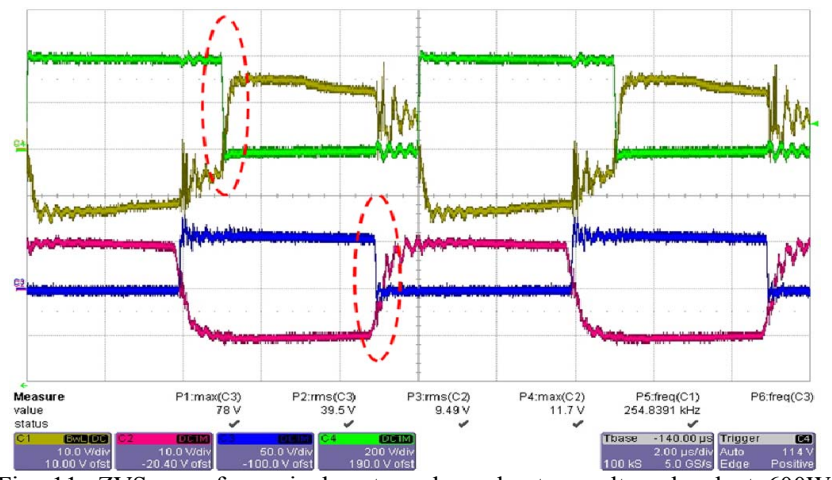

Fig. 11. ZVS waveforms in boost mode under two-voltage-level at $600 \mathrm{~W}$ output power. CH1: $V_{G S 6}(10 \mathrm{~V} / \mathrm{div})$; $\mathrm{CH} 2: V_{G S 4}(10 \mathrm{~V} / \mathrm{div})$; $\mathrm{CH} 3: V_{D S 4}(50$ V/div); CH4: $V_{D S 6}(200 \mathrm{~V} /$ div $)$.

A 1-kW prototype with discrete components and its integrated generation with the proposed PIM module have been constructed as shown in Fig.7 and Fig.8 respectively. The integrated converter has the same electric parameters as those of discrete generation, but has a much smaller profile and total volume. In order to make a fair comparison, the same MOSFETs and capacitors are used. The switching MOSFETs $\mathrm{S}_{1} \sim \mathrm{S}_{4}$ are implemented by IRFP4568. The high voltage side MOSFETs $S_{5}$ and $S_{6}$ are realized by Vishay SIHG20N50C. The operation specifications for the hybrid converters can be found in Table I. 


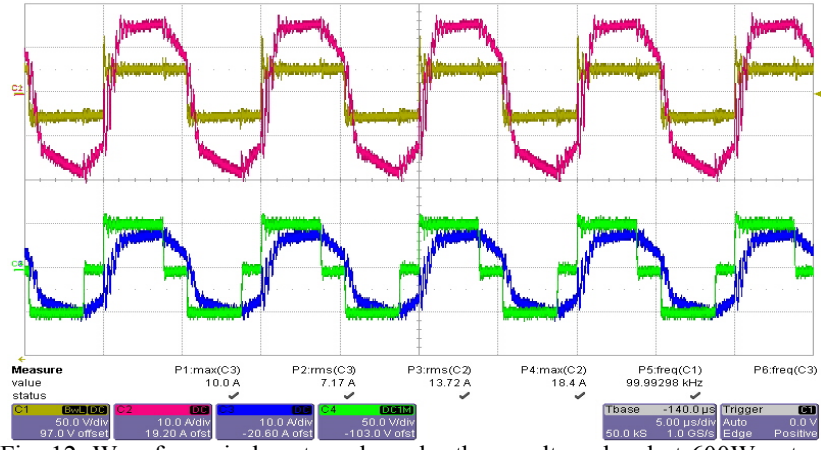

Fig. 12. Waveforms in boost mode under three-voltage-level at $600 \mathrm{~W}$ output power. CH1: $V_{A N}(50 \mathrm{~V} / \mathrm{div})$; $\mathrm{CH} 2: i_{\mathrm{T} 1}(10 \mathrm{~A} / \mathrm{div}) ; \mathrm{CH} 3: i_{\mathrm{T} 2}(10 \mathrm{~A} / \mathrm{div}) ; \mathrm{CH} 4$ : $V_{A B}(50 \mathrm{~V} / \mathrm{div})$.

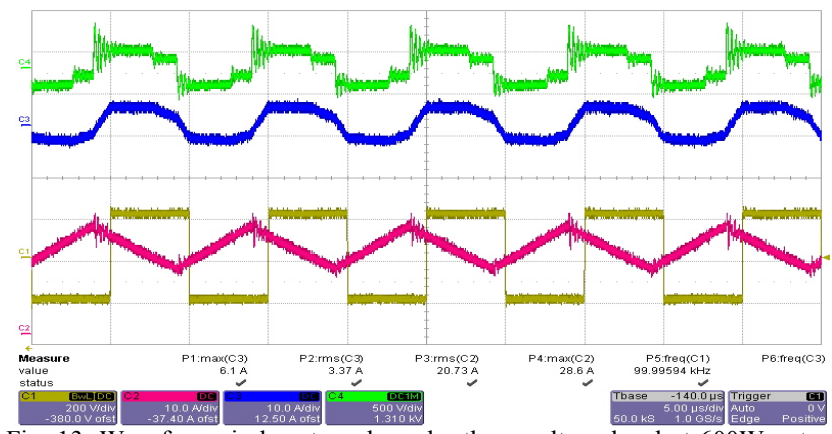

Fig. 13. Waveforms in boost mode under three-voltage-level at $600 \mathrm{~W}$ output power. $\mathrm{CH} 1: V_{C O}(200 \mathrm{~V} / \mathrm{div}) ; \mathrm{CH} 2: i_{\mathrm{L} 1}(10 \mathrm{~A} / \mathrm{div}) ; \mathrm{CH} 3: i_{\mathrm{L} 2}(10 \mathrm{~A} / \mathrm{div}) ; \mathrm{CH} 4$ : $V_{M O}(500 \mathrm{~V} /$ div $)$.

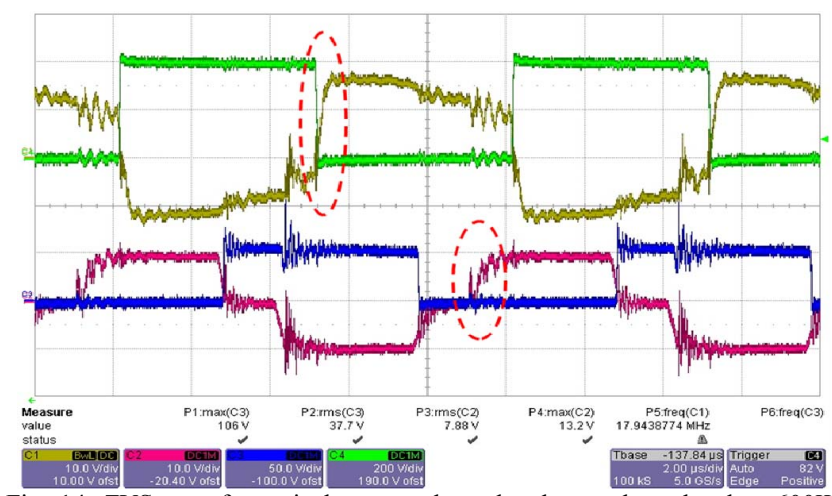

Fig. 14. ZVS waveforms in boost mode under three-voltage-level at $600 \mathrm{~W}$ output power. CH1: $V_{G S 6}(10 \mathrm{~V} / \mathrm{div}) ; \mathrm{CH} 2: V_{G S 4}(10 \mathrm{~V} / \mathrm{div})$; $\mathrm{CH}$ : $V_{D S 4}(50$ $\mathrm{V} / \mathrm{div}) ; \mathrm{CH} 4: V_{D S 6}(200 \mathrm{~V} / \mathrm{div})$.

Fig.9, Fig.10 and Fig.11 show the waveforms working under the two-voltage-level mode (duty cycles of $\mathrm{S}_{3}$ and $\mathrm{S}_{4}$ are $50 \%$ ) in the integrated generation at $600 \mathrm{~W}$ output power. Fig.9 shows the plots of the primary voltages $\left(\mathrm{CH} 1: V_{A N}\right.$ and CH4: $\left.V_{A B}\right)$ and currents $\left(\mathrm{CH} 2: i_{T 1}\right.$ and $\left.\mathrm{CH} 3: i_{T 2}\right)$ for the two transformers $T_{1}$ and $T_{2}$ respectively. Fig.10 represents the waveforms of voltages $\left(\mathrm{CH} 1: V_{C O}\right.$ and $\left.\mathrm{CH} 4: V_{M O}\right)$ on high voltage side and the currents of boost inductor $\left(\mathrm{CH} 2: i_{L I}\right)$ and auxiliary inductor $\left(\mathrm{CH} 3: i_{L 2}\right)$. Zero-voltage turn on for the MOSFETs can be proved in Fig.11. For simplification, only ZVS waveforms for the switching $\mathrm{S}_{4}$ and $\mathrm{S}_{6}$ are shown. In fact, all of MOSFETs in the circuit can implement zerovoltage turn on at this power. Fig.12, Fig.13 and Fig.14 show

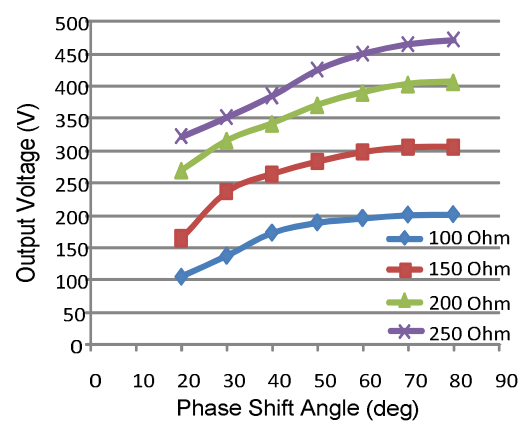

Fig. 15. The relationship between output voltage and phase shift angle at the three-voltage-level mode for the PIM converter.

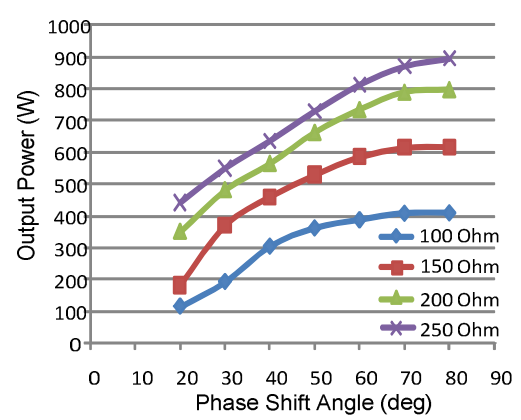

Fig. 16. The relationship between output power and phase shift angle at the three-voltage-level mode for the PIM converter.

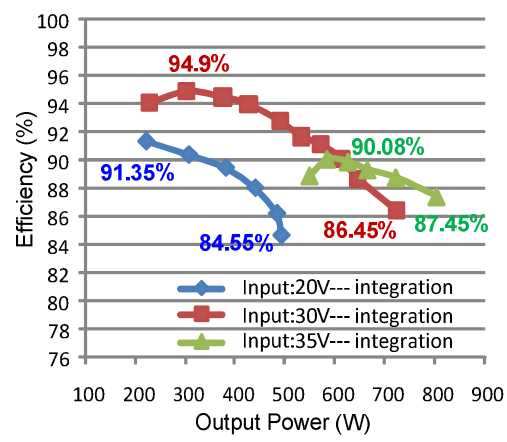

Fig. 17. The efficiency comparisons among the different input voltages at $400 \mathrm{~V}$ output voltage and the three-voltage-level mode for the PIM converter.

the waveforms under three-voltage-level mode (duty cycles of $S_{3}$ and $S_{4}$ are $35 \%$ ) in the integrated generation at $600 \mathrm{~W}$ output power. The plotted parameters in each figure are corresponding with the previous figures for two-voltagelevel. The peak current has been dropped down due to the negative voltage on the auxiliary inductor $\mathrm{L}_{2}$ during that period which caused by the duty cycle control of $\mathrm{S}_{3}$ and $\mathrm{S}_{4}$. Since the peak current is reduced, many advantages can be found including lower MOSFET stresses, lower power loss and lower core loss in the auxiliary inductor $\mathrm{L}_{2}$. As the same as two-voltage-level mode, zero-voltage turn on for all of MOSFETs can be realized as well.

By controlling the phase shift of the voltages between $V_{C O}$ and $V_{M O}$, the power transferred over the transformers as well 


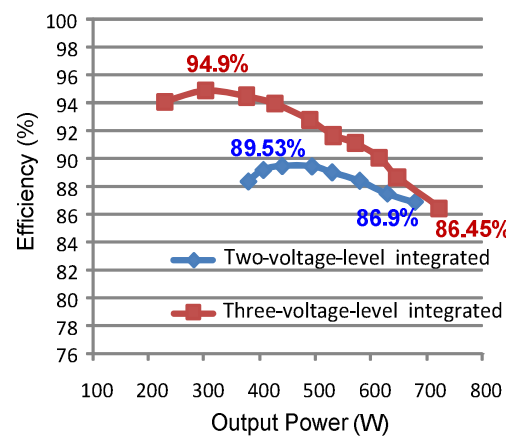

Fig. 18. The efficiency comparisons between the two-voltage-level mode and three-voltage-level mode at $30 \mathrm{~V}$ input voltage and $400 \mathrm{~V}$ output voltage for the PIM converter.

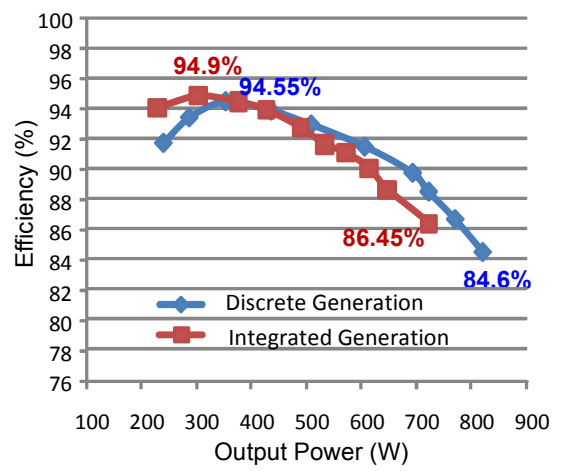

Fig. 19. The efficiency comparisons between the discrete generation and the PIM generation under three-voltage-level mode at $30 \mathrm{~V}$ input voltage and $400 \mathrm{~V}$ output voltage.

as the high side DC voltage can be precisely controlled. Fig. 15 and Fig. 16 show their relationships respectively.

Different power loads are corresponding with different output voltages when the phase shift angle is given, which means the load effects the power flow as well. The maximum power flow occurs at $\delta=\pi / 2$. Several efficiency comparison curves are shown in Fig.17 19. Different input voltages are corresponding with different power ranges this is due to the fact that the transferred power range is determined by the leakage inductance of the transformers, auxiliary inductor $L_{2}$, voltages between two sides of the transformer and switching frequency. When the converter is running under two-voltagelevel mode $(\mathrm{D}=0.5)$, the transferred power can be found [12],

$$
P=\frac{V_{C O} \cdot V_{M O} \cdot \delta \cdot(\pi-\delta)}{\omega \cdot \pi \cdot L_{2}}
$$

The power loss are mainly contributed by the conduction loss of MOSFETs on low voltage side, winding loss and core loss of PIM module, the core loss of auxiliary inductor $L_{2}$. It needs to be noted that bigger phase shift angle will cause the higher current stresses and RMS currents of the converter and the reactive power transferred also increases, which leads to higher current stresses of the switch devices and higher conduction losses. Fig.18 shows the efficiency comparisons between the two-voltage-level mode and three-voltage-level mode at $30-\mathrm{V}$ input and $400-\mathrm{V}$ output voltage for the PIM converter. The efficiency under three-voltage-level mode has been significantly improved this is due to the fact that the peak current can be reduced by the duty cycle control so that there are benefits on the conduction losses of converter as well as the core loss of auxiliary inductor $L_{2}$. The measured efficiencies as a function of output power of the discrete converter and PIM converter are shown in Fig.19. From these results, it can be seen that the PIM module has a much smaller profile and volume, but similar electrical performance. The reason for the efficiency difference appearing at high power between the two converters might be higher fringing flux which causes higher AC winding loss.

\section{CONCLUSION}

This work proposes a new idea to integrate magnetics in the hybrid DC/DC converter. Two transformers and one boost inductor are integrated into E-I-E planar module. The proposed PIM module has fewer components, almost half profile than the discrete components, low cost without sacrificing electrical performance. The experimental results verified that the proposed PIM module has been successfully applied into a novel hybrid DC/DC converter while the full functions of the converter are not sacrificed.

The lack of the work and future improvement needs to be pointed out here: A smaller auxiliary inductor $L_{2}$ leads to a smaller phase shift while transferring the same amount power. In the other word, a smaller phase shift inductor can transfer more power. However, a smaller phase shift inductor is not suitable for this converter because the current on the switching $\mathrm{S}_{2}$ is much higher than the others due to the boost structure in the hybrid circuit, the supplied power is therefore limited. The authors are trying to improve the topology so that more power can flow through the PIM module, even the auxiliary inductor $L_{2}$ can be integrated into PIM module as well.

\section{REFERENCES}

[1] Z. Zhang, O. C. Thomsen and M. A. E. Andersen, "Wide input voltage range bidirectional DC-DC converter for fuel cell and supercapacitor in UPS system," IEEE PEDS, 2009, pp.706-711.

[2] W. Chen, G. Hua, D. Sable and F. C. Lee, "Design of high efficiency, low profile, low voltage converter with integrated magnetics," IEEE APEC, 1997, pp. 911-917.

[3] P. Xu, Q. Wu, P. Wong and F. C. Lee, "A novel integrated current doubler rectifier," IEEE APEC, 2000, pp. 735-740.

[4] P. Xu, M. Ye, P. Wong and F. C. Lee, "Design of $48 \mathrm{~V}$ voltage regulator modules with a novel integrated magnetics," IEEE Trans. on Power Electron., vol.17, no.6, pp.990-998, Nov.2002

[5] Søren Petersen, "Improved geometry of integrated magnetics for the hybridge topology," Proceedings of the Sixth European Conference, European Space Agency, ESA SP-502, p.241-247, May, 2002.

[6] J. Sun, V. Mehrotra. "Orthogonal winding structures and design for planar integrated magnetics," IEEE Trans. on Ind. Electron., vol. 55, no. 3, pp.1463-1469, March, 2008.

[7] M. Meinhardt, M. Duffy, T. O. Donnell, S. O. Reilly, J. Flannery and C.O. Mathuna, "New method for integration of resonant inductor and transformer design, realisation, measurements" IEEE APEC, 1999, pp. $1168-1174$ 
[8] R. Chen, S. J. T., van Wyk J.D. "Design of planar integrated passive module for zero-voltage-switched asymmetrical half-bridge PWM converter," IEEE Trans. on Ind. Appl., Vol. 39, no.36, pp.1648-1655, Nov.-Dec. 2003

[9] P.A. J. van Rensburg, J.D. van Wyk and J.A. Ferreira, "Design, prototyping and assessment of a $3 \mathrm{~kW}$ integrated LCT component for development in various resonant converters," IET Power Electron., Vol. 2, no.5, pp.535-544, 2009

[10] D. Xu, C. Zhao and H. Feng, "A PWM plus phase-shift control bidirectional DC-DC converter," IEEE Trans. on Power Electron., vol.19, no.3, pp.666-675, May.2004.

[11] M. Nymand and M. A. E. Andersen, "High-efficiency isolated boost dc-dc converter for high-power low-voltage fuel-cell applications," IEEE Trans. on Ind. Electron., Vol. 56, no.2, pp.505-514, Feb. 2010.

[12] J. Wang, F.Z. Peng, J.Anderson, A.Joesph and R. Buffenbarger, "Low cost fuel cell converter system for residential power generation," IEEE Trans. on Power Electron., Vol. 19, no.5, pp.1315-1322, Sep. 2004.

[13] Y. Jang and M.M. Jovanovic', "A new PWM ZVS full-bridge converter," IEEE Trans. on Power Electron., Vol. 22, no.3, pp.987-994, May. 2007.

[14] T. Mishima, Y. Ooue, Y. Fukumoto, M. Nakaoka, "An active rectifierphase shifted ZVS-PWM DC-DC converter with HF planar transformer-link for RF plasma power generator," IEEE PEDS, 2009, pp.712-717.

[15] D. Liu and H. Li., "A ZVS bi-directional DC-DC converter for multiple energy storage elements," IEEE Trans. on Power Electron., Vol. 21, no.5, pp.1513-1517, Sept. 2006.

[16] H. Tao; A. Kotsopoulos, J.L. Duarte, M.A.M. Hendrix, "Transformercoupled multiport ZVS bidirectional DC-DC converter with wide input range," IEEE Trans. on Power Electron., Vol. 23, no.2, pp.771-781, March. 2008 